\title{
TROMBOCITOPENIA SEVERA COM MANIFESTAÇÃO BUCAL ASSOCIADA À INFECÇÃO PELO HIV - RELATO DE CASO
}

Joslei Carlos BOHN, Edson Paulo de LEMES, Vinicius Villas Boas PETRONI, Cassiano Lima CHAIBEN, Antonio Adilson Soares de LIMA

As plaquetas sanguíneas representam fragmentos citoplasmáticos anucleados presentes no sangue e que atuam ativamente no processo de coagulação sanguínea. Quando a quantidade de plaquetas no sangue é inferior a $150.000 / \mathrm{mm}^{3}$, diz-se que o indivíduo apresenta trombocitopenia. A causa deste distúrbio pode estar associada a diversas condições patológicas. Pacientes com trombocitopenia possuem maior tendência a apresentar fenômenos hemorrágicos e sua descoberta costuma ser inicialmente notada por causa de lesões bucais. O objetivo deste trabalho é descrever um caso de trombocitopenia em um paciente HIV positivo. Paciente do sexo masculino, 39 anos de idade, foi encaminhado ao Hospital Oswaldo Cruz (Curitiba/PR) com queixas de perda de peso e hemorragia bucal. O paciente tem histórico de tuberculose pulmonar e é portador do HIV. O exame físico intra-oral revelou a presença de lesões crostosas de aspecto hemorrágico sobre o vermelhão dos lábios superior e inferior, hematoma em palato mole e equimoses na pele da face. O diagnóstico de trombocitopenia foi estabelecido baseado nos exames hematológicos (contagem de plaquetas: $108 / \mathrm{mm}^{3}$ ), histopatológico e pelas características clínicas do paciente. O paciente foi tratado por meio da reposição de plaquetas e pela reintegração da terapia com antirretrovirais, cinco semanas depois, observou-se a remissão total das lesões.

Palavras chave: Trombocitopenia; Plaquetas; Contagem de plaquetas; Lábio; Imunossupressão. 